\title{
Application of a Productivity Function to Assess Network Performance During Mass Evacuations
}

\author{
Zhao Zhang ${ }^{1}$, Scott Parr $^{2 *}$ and Brian Wolshon ${ }^{3}$ \\ ${ }^{1}$ Beihang University, School of Transportation Science and Eng. \\ ${ }^{2}$ California State University, Fullerton, Department Civil \& Environmental Eng. \\ ${ }^{3}$ Gulf Coast Center for Evacuation and Transportation Resiliency, Louisiana State \\ University, Department of Civil and Environmental Eng. \\ ${ }^{1}$ zhaozhang1111@gmail.com, ${ }^{2}$ sparr@fullerton.edu, ${ }^{3}$ brian@rsip.lsu.edu
}

\begin{abstract}
The ever-increasing processing speed and computational power of computers and simulation systems has led to correspondingly larger, more sophisticated representations of evacuation traffic processes. Today, micro-level analyses can be conducted for megaregion-level hurricane evacuations involving millions of vehicles, spanning thousands of miles of roadway over multiple states, lasting over several days, and incorporating the intermodal exchange of evacuees. However, the effort required to build such models and the volume of output data they produce also presents difficulties for analysts as they code networks, generate demand, model control elements and then calibrate results and interpret output.

The goal of this paper was to quantify and describe the operational conditions of evacuation traffic "network productivity." The concepts suggest that maximum production, and therefore trip completion, is realized when the network achieves the highest rate of vehicles-miles traveled in a time interval. In this research, a megaregion evacuation model was used to quantify the average network velocity, demand and network length which was necessary to estimate the network productivity. The results showed that network productivity exhibited a peaking characteristic. This suggested that network productivity can be maximized on a macroscopic scale as a function of demand. With knowledge of the optimal network demand, emergency planners can develop evacuation management plans which reach and maintain traffic at an optimal demand level. When this optimal demand level is exceeded, evacuees are likely to experience inordinately lengthy delays. Conversely, conditions with demand levels below the optimal level will result in reduced overall network productivity and fewer trips completed per time interval.
\end{abstract}

Keywords: Network Productivity, Evacuation, Network Simulation, Megaregion

\section{Introduction}

The past 20 years has seen the emergence of traffic simulation as an effective tool for the planning and analysis of evacuations. Some of the earliest application of simulation began with the use of macroscopic modeling systems for evacuation time estimates for nuclear power plant emergencies in the late 1970's [1]. More recently, the ever-increasing processing speed and computational power of computers and simulation systems has led to correspondingly larger, more sophisticated, and detailed representations of evacuation traffic processes. Today, micro-level analyses are able to be conducted for megaregionlevel hurricane evacuations that span multiple states over several days and include the intermodal exchange of evacuees, millions of vehicles, and thousands of miles of roadway

${ }^{*}$ Corresponding Author 
[2]. Such models are useful for bloth theoretical study and practical application because they are able to demonstrate the influence of various assumptions and policies, as well as capacity and demand management strategies. This can be used to guide emergency response decision-making on multi-state regional levels. However, the effort required to build such models and the volume of output data they produce also present difficulties for analysts; as they code networks, generate demand, model control elements and then calibrate results and interpret output. Collectively, these issues create a classic transportation "Big Data" problem.

The research described in this paper employed a microscopic simulation model of the Gulf Coast megaregion of the United States. The megaregion model was originally developed to examine the effects of temporal and spatial evacuation strategies that regulated demand and added road capacity. The novel approach described in this paper used output performance measures from this model to maximize the "trip completion rate" of the network. Geroliminis and Daganzo (3) showed that trip completion rate (the rate at which vehicles arrive at their destination) is proportional to "network productivity." Where productivity, as defined by the researchers, is the product of average flow and network length and is quantified in vehicle-miles per hour (vmph). This suggest that maximum production and therefore trip completion, is realized when the network achieves the highest rate of vehicles-miles traveled in a time interval; i.e., when the most vehicles are traveling at the fastest speed. It is theorized that trip completion rate and network productivity can be used as simple but highly descriptive measures of efficiency that can be applied by both transportation and emergency management officials to assess the overall ability of a regional road network to safely and efficiently permit evacuees to move from higher risk areas to lower risk areas.

In this research, the megaregion evacuation model was used to generate average travel speeds corresponding to varying disaster scenarios, traffic management plans and evacuee demand. The average travel speed (ATS) was plotted against demand for each scenario. From this plot, four functions (linear, parabolic, logarithmic and sigmoidal) were fitted to the data points to estimate $\mathrm{v}(\mathrm{n})$, a function relating the average travel speed of a network to and total network demand. Four functions were selected because the true form of the $\mathrm{v}(\mathrm{n})$ function is unknown. Therefore, to estimate $\mathrm{v}(\mathrm{n})$, a series of functional forms had to be tested. The network productivity function was used to identify the optimum evacuation demand corresponding to the maximum trip completion rate. It is thought that this information can be used by decision makers to select traffic management strategies that meter network demand as close as possible to an optimal level. When used in conjunction with phased evacuation strategies or evacuation route metering, the network demand can be manipulated to ensure the maximum evacuation productivity and trip completion rate.

The following sections of this paper provide background and context to the model, the need for this research, and describe the research methods, its results and ways that the techniques described here could be applicable to any location and set of conditions; routine or emergency. Although this research focuses on the concept of network productivity and its relationship to trip completion rate to address some of the "Big Data" problems, associated with evacuation modeling, the results can be applied to virtually any large-demand transportation condition, including planned major events. The Methods section describes the megaregion model and the theoretical proofs used to generate the network productivity function. The Experimental Results section demonstrates the model fit and intuitive nature of the theory application. The Validation Network section uses a theoretical grid network to validate the results observed in the megaregion model and the Conclusion section discusses the research results, broader application and direction of planned and ongoing work. 


\section{Background}

Over the past century the world has experienced an increasing pattern of urbanization and concentrated population growth that has led to the emergence of megaregions. Megaregions are characterized by the merging of once separate cities into geographically large areas of continuous population [4]. Examples of megaregions in the United States (US) include the northeastern Atlantic seaboard area from Boston south through New York and Philadelphia then into Washington D.C. and the on the west coast from San Diego north through Los Angeles and into Santa Barbara. Worldwide, significantly larger megaregions can be found especially in Europe, South America, and throughout Asia. Megaregions share common political, geographic, cultural, economic, and historical ties. They also share transportation linkages and susceptibility to natural and manmade disasters. An example of this was seen in the devastating effects of Super Storm Sandy on the US megaregion in 2012, the 2011 earthquake, tsunami and Natech nuclear power plant emergency in Japan, and Hurricanes Katrina and Rita which hit the Gulf Coast megaregion back-to-back in 2005.

Transportation simulation modeling of a megaregion on a microscopic scale is currently an exploratory concept in traffic engineering. Modeling millions of individual vehicles and their interactions within a network was only recently, computationally possible without supercomputers. The advantages of microscopically modeling a megaregion are that it can demonstrate how small disturbances in traffic flow can propagate quickly throughout large networks if not mitigated properly. For example, a bottleneck on a freeway link that creates a queue to form on on-ramps, which then spills back onto arterial roadways causing surface street gridlock. At the demand levels generated in evacuations, this can happen within minutes. This phenomenon can be captured using meso or macroscopic models, but not with the detail and intricacies of a microscopic model. These smaller scale models allow for better understanding of the causes of breakdowns and congestion propagation.

Among the first application of traffic simulation modeling to evacuation was a study conducted to estimate the evacuation time of Three Mile Island in Pennsylvania [5]. Later studies were focused on testing and evaluating evacuation management strategies such as contraflow [6,7] and phasing [8] on small urban networks. Research conducted on larger regional scales have typically used macroscopic traffic models and have been primarily focused on clearance and network delay [9-11]. Microscopic modeling on a city-wide scale has been used to test traffic management strategies and modeling techniques in the Houston and New Orleans area [12, 13]. More recent studies have been conducted on megaregion networks. Chiu et al., (2008) and Dixit et al., (2011a) conducted regionalscale simulation studies to evaluate regional impacts of various evacuation strategies for the Houston-Galveston area during Hurricane Rita and the Louisiana region during Hurricane Katrina, respectively [12, 13]. So and Daganzo (2010) developed priority rules for evacuation routes to increase efficiency [29]. Also, Daganzo and So (2011) proposed an evacuation network management strategy to maximizing performance [30]. Both of these works find that evacuation time is minimized when capacity, either of a route or a network is fully utilized. Recent research as been extended to megaregions. Zhang et al., (2013) modeled US Gulf Coast megaregion evacuation scenarios using macroscopic measures of performance under varying levels of demand and proactive evacuation traffic management strategies like contraflow [2]. Further megaregional study by Zhang et al., $[21,31]$ showed that by coordinating traffic demand inconsecutive time windows, the network traffic performance can be improved by $24 \%$ to as much as $64 \%$. However, the optimization of evacuation demand management for complicated scenarios, such as multiday evacuations in urban or regional network, has not yet been undertaken. Because of this, the optimization of demand assignment pattern in regional evacuation remains as a significant challenge. 
The concept of traffic system productivity was first introduced by Daganzo (2005). In this work, flow-sums at evenly space intervals were used to provide an indication of vehicle-miles-traveled (VMT) and used as a proxy for productivity. Later, Daganzo (2007) showed the relationship between trip completion rate and the number of vehicles inside an urban network. This work led to the realization that network productivity was proportional to trip completion and a function of demand [3]. The relationship between productivity and trip completion was later showed to be constant using detector data and floating vehicle probes [16]. Experiments conducted on the Yokohama (Japan) and San Francisco road networks show that a stable MFD linking space-mean speed, flow, and density exists in large urban areas [22]. Since this early work, research has been conducted to show the existence of MFD in other countries including the US [23], Greece [24], France [25], etc. Mazloumian et al., (2010) shows that the relationship between network average flow and the variation of network density, i.e., average density and spatial variability of vehicle densities determine the shape of the MFD, and the MFD is also related to the number of full links [26]. Geroliminis and Sun (2011) also proves that spatial distribution of vehicle density in the network is one of the key components that affect the scatter of an MFD and its shape [27]. Zhu et al., (2012) verify that the shape of MFD curve is influenced by network topology, traffic demand, and traffic load pattern based on traffic data collected in Beijing, China [28].

\section{Research Methodology}

The development of the evacuation productivity function for the megaregion network in this research was accomplished within a framework of several tasks. The first task was the building of a "base model" which incorporated the links, nodes and traffic control features of the megaregion road network as well as the traffic demand. The next task was the creation of a series of evacuation scenarios of theoretical hazards with associated response conditions. The third task extracted the network average travel speed, and analyzed it within the context of the corresponding demand and response conditions. Curve fitting was then used to estimate a function relating average travel time and network demand, $v(n)$. In the fourth task, this function was used to compute the evacuation productivity function. This was then validated using a theoretical urban grid simulation network.

\subsection{Network Productivity}

Network productivity per unit length as formulated by Geroliminis and Deganzo (2008) was given in Equation (1). In this sense, productivity can be seen as the weighted average of link flows, essentially quantifying the efficiency of the network in transporting vehicles. The aim of this research is to quantify this measure for a megaregion evacuation to better understand the relationship between evacuation demand, network characteristics, and the overall evacuation performance. Link accumulation was the number of vehicles on a given link segment $i$ with length $l_{i}$ and density $k_{i}$, Equation (2). The established relationship between link flow $\mathrm{q}_{\mathrm{i}}$, link density $\mathrm{k}_{\mathrm{i}}$ and travel speed on the link $\mathrm{v}_{\mathrm{i}}$ was given in Equation (3). Through substitution, the productivity of a single link was expressed in several forms, Equation (4). When the velocity was represented as a continuous function of demand $v(n)$, the productivity was estimated on a network level, Equation (5). This relationship can therefore be used to express network productivity per unit length as defined in Equation (6).

$$
\begin{aligned}
& q^{w}=\frac{\sum_{i} q_{i} l_{i}}{\sum_{i} l_{i}} \\
& n_{i}=k_{i} l_{i}
\end{aligned}
$$




$$
\begin{aligned}
& q_{i}=v_{i} k_{i} \\
& q_{i} l_{i}=v_{i} k_{i} l_{i}=v_{i} n_{i} \\
& \sum_{i} v_{i} n_{i} \cong v(n) n \\
& q^{w}(n)=\frac{\sum_{i} q_{i} l_{i}}{\sum_{i} l_{i}}=\frac{\sum_{i} v_{i} k_{i} l_{i}}{\sum_{i} l_{i}}=\frac{\sum_{i} v_{i} n_{i}}{\sum_{i} l_{i}} \cong \frac{v(n) n}{\sum_{i} l_{i}}
\end{aligned}
$$

The remaining portion of the methodology aims to show through simulation that Equation (1) developed by Geroliminis and Deganzo (2008) was both mathematically and in practice, equivalent to Equation (6). The simulation model was used to quantify the average network velocity, network demand and network length which was necessary to estimate the network productivity.

\subsection{Simulation Base Model Development}

A microscopic traffic simulation of a megaregion evacuation was developed to explore the applicability of the proposed network productivity formulation. The megaregion simulated in this study spanned New Orleans, Louisiana to Houston and Galveston Texas, and included the areas of Baton Rouge, Lafayette, Lake Charles and Beaumont. While not the most populated megaregion in the U.S., this area is growing in population and economic importance, as it serves as a major domestic energy hub for the nation. The region was selected based on its extensive history of transportation modeling, simulation study, and analysis conducted on hurricane evacuation.

The megaregion model was coded in the TRAMSIMS traffic simulation system. Originally developed for travel forecasting and emission analysis, TRAMSIMS was used in this research because of its ability to generate and simulate synthetic populations based on actual census data, and create spatial and temporal traffic patterns. The development of the megaregion traffic simulation model in this project was accomplished within a framework of three primary tasks. The first was the creation of a "base model," which included the link, node, and control features of the regional road network, and then its calibration and validation based on the 2005 Hurricane Katrina and 2008 Hurricane Gustav evacuations. The second step was to develop synthetic evacuee population based on 2010 census data. The third step the creation of a series of evacuation scenarios based on theoretical hazards and response conditions. TRAMSIMS is particularly suited for large scale evacuation traffic analysis because the roadway network is generated from geographic information system (GIS) shapefiles. This data was readily available from existing road network files developed by the Metropolitan Planning Organizations of the six major municipalities within the region. These six separate road networks were merged into one megaregion using GIS software. The "empty spaces" between these six regions were manually connected using various online and printed maps. This made lead to an accurate link-node network to build the remaining model components upon. The resulting megaregion network is depicted in Figure 1. A more detailed description of the megaregion model, its calibration and validation for the evacuation scenarios, can be found in Zhang, Spansel and Wolshon (2013) [2]. 


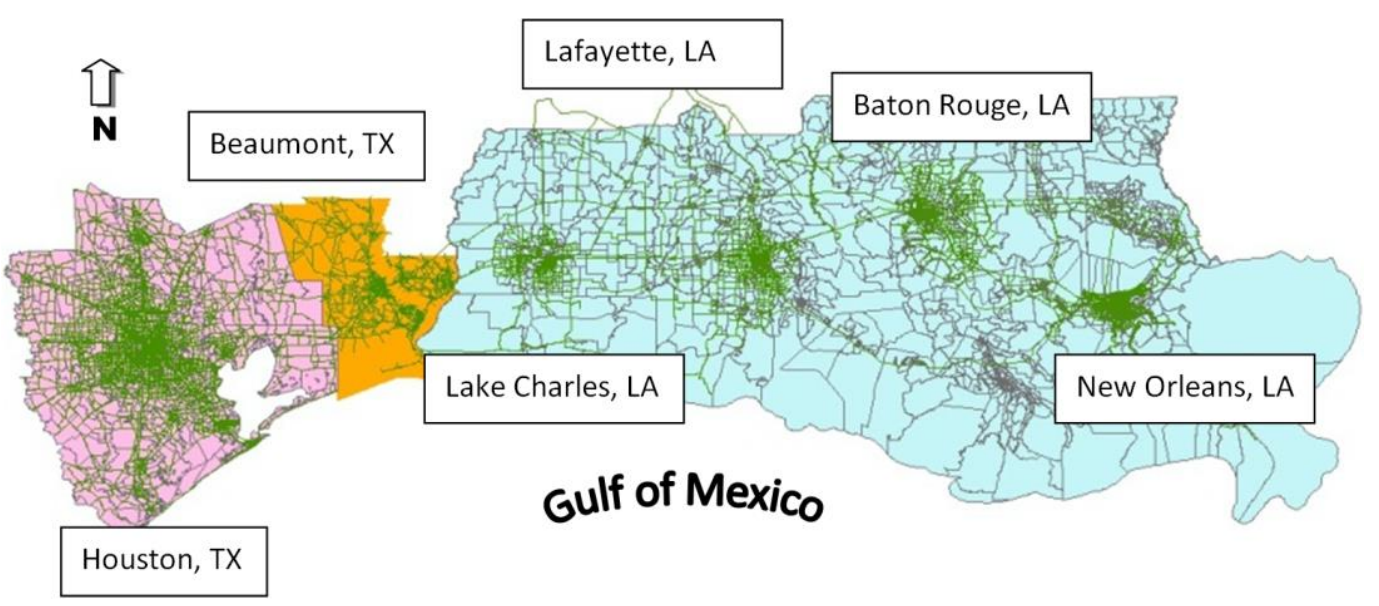

Figure 10. Gulf Coast Megaregion Network

\subsection{Evacuation Demand Forecast}

The evacuation demand generation; specifically evacuee origin, destination and departure time were also modeled in TRAMSIMS. The synthetic evacuee population was created using 2010 US Census data. A mathematical representation of the population for each transportation analyses zone (TAZ) was generated to statistically match the demographic information contained in the US Census data. The TAZs were used to represent the evacuee origins in the model. For areas in between the six major areas of the megaregion, where TAZ information was not available, voting district (VD) information from the 2010 US Census was used. The methodology described by Cheng, Wilmot and Baker (2008), was used to represent the evacuee origins within these areas. The 2010 Census Summary File 1 (SF1) data was used to assign household and population values to each TAZ and VD.

The evacuee departure time was modeled with a time dependent sequential logit model (TDSLM). This model was developed by Gudishala (2012) using 2008 Hurricane Gustav evacuation survey information. This model estimated the evacuation participation rate and departure times for each of the metropolitan regions and coastline areas in Louisiana and Texas. The evacuation participation rate generated varies from area to area in accordance with the levels of threat perceived from the hypothetical storms.

The evacuee destination choice model was applied from research conducted by Cheng, Wilmot and Baker (2008). This model assigns a probability to each destination direction based on its distance from an origin, the level of hazard threat at the destination, and the population of the destination. This methodology employs a multinomial logit model (MNL) to estimate the destination choice probability for each evacuee. The MNL model was developed using survey information collected from 1999 Hurricane Floyd evacuees from South Carolina. Using the synthetic population TAZs and VD as origins and the MNL choice probabilities as destinations, an evacuation origin-destination (OD) was developed for each time-interval in accordance with the departure curve generated from the TDSLM. Vehicles are routed in TRANSIMS using the Router and Simulator modules, capable of preforming static and dynamic user equilibrium routing strategies.

\subsection{Scenario Development}

The evacuation scenarios for this research were based on two historical hurricanes with tracks that affected the entire model region (Storm Track 1 and Storm Track 2) and three contraflow plans (No Contraflow Plan, Contraflow Plan 1 and Contraflow Plan 2). The demand levels of the evacuation varied based on the timing and level of threat posed by each storm. Storm Track 1 was coupled with each of the three contraflow plans and was 
simulated at four different demand levels. Storm Track 2 was simulated using Contraflow Plan 2 and seven demand levels. This generated a total of 19 unique scenarios.

Storm Track 1 was based on the track of 2008 Hurricane Gustav which made landfall in the megaregion just south of New Orleans, Louisiana. Strom Track 2 followed the track of an unnamed hurricane in 1914 that made landfall on the eastern side of the megaregion and traveled to the west [19]. The tracks of both hurricanes are illustrated in Figure 2. The storm tracks dictated the locations of shelters thus varying demand placed on individual links.

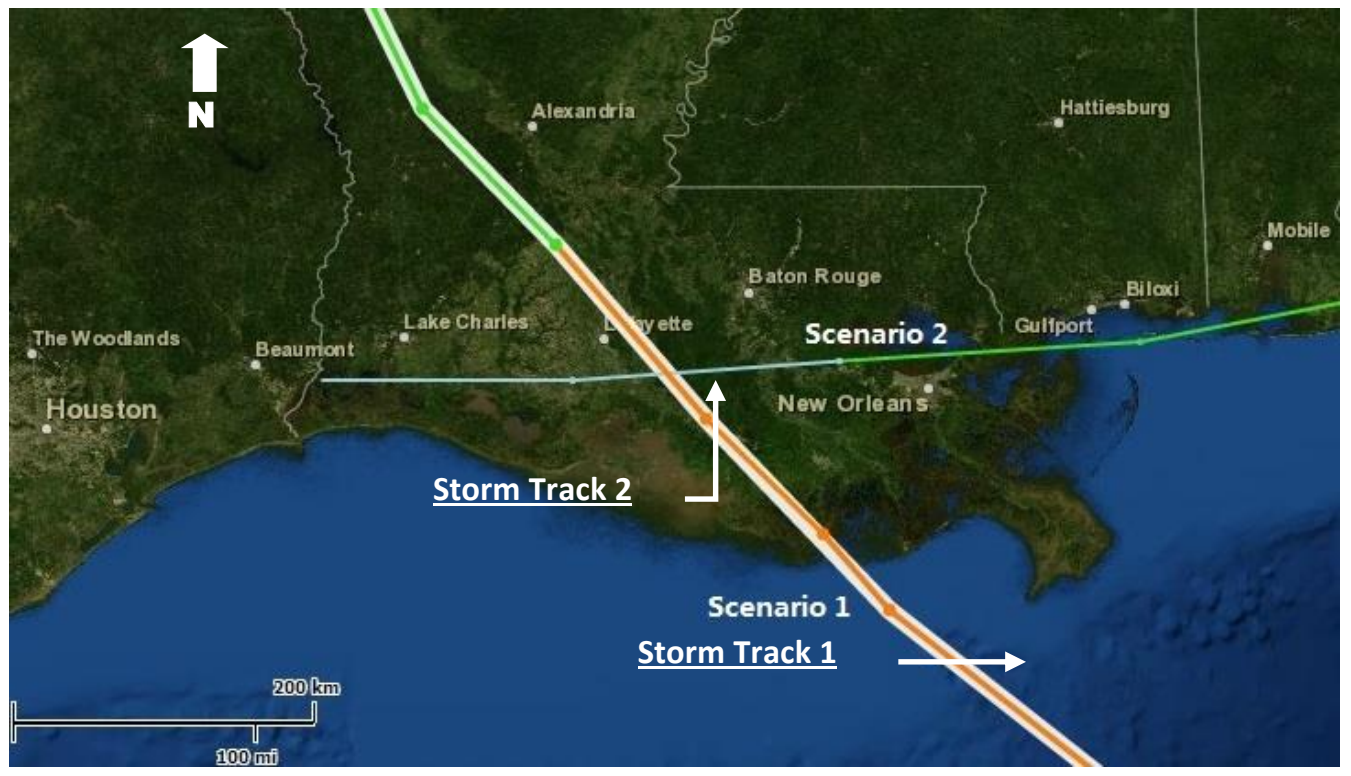

Figure 2. Hurricane Tracks

The MNL destination choice model developed by Cheng, Wilmot, and Baker (2008) was applied to the two storm track scenarios. The MNL model found that for storm track 1, most households prefer to evacuate to the west (55\%) with the remaining households distributed approximately evenly between the East, North, Northeast and Northwest. The MNL results for storm track 2 found an even distribution of evacuees to the West, North and Northwest with no evacuees preferring an Eastbound or Northeast bound destinations. This result was logical given perceived threat of storm track 2

In additional to the No Contraflow Plan, two additional plans were evaluated in this research. Contraflow Plan 1 was derived from the actions taken by the Louisiana State Police and Department of Transportation and Development during (DOTD) the 2008 Hurricane Gustav evacuation of south Louisiana. Contraflow was used on several links beginning at 4:00am on the second day of a two-day evacuation. Contraflow Plan 2 was initiated on the same links as Contraflow Plan 1 but operated for the entire second day of the two-day evacuation. The operational time period and location of each contraflow plan are summarized in Table 1.

Table 1. Contraflow Plan Implementation

\begin{tabular}{||c|c|c||c||}
\hline Road Name & Start Time & End Time & Contraflow Plan \\
\hline $\begin{array}{c}\text { Eastbound I-10 } \\
\text { between New Orleans to } \\
\text { Laplace, LA }\end{array}$ & $\begin{array}{c}\text { 4:00 am, first day of } \\
\text { evacuation }\end{array}$ & $\begin{array}{c}12: 00 \text { am, Second day } \\
\text { of evacuation }\end{array}$ & Plan 1 \\
\hline $\begin{array}{c}\text { Northbound I-10/I-55 } \\
\text { between Hammond, LA } \\
\text { and Mississippi }\end{array}$ & $\begin{array}{c}4: 00 \text { am, first day of } \\
\text { evacuation }\end{array}$ & $\begin{array}{c}12: 00 \text { am, Second day } \\
\text { of evacuation }\end{array}$ & \\
\hline
\end{tabular}




\begin{tabular}{|c|c|c|c|}
\hline $\begin{array}{l}\text { Northbound I-59, north } \\
\text { to the I-10/I-12/I-59 } \\
\text { interchange }\end{array}$ & $\begin{array}{l}\text { 4:00 am, first day of } \\
\text { evacuation }\end{array}$ & $\begin{array}{l}\text { 12:00 am, Second day } \\
\text { of evacuation }\end{array}$ & \\
\hline $\begin{array}{l}\text { Northbound I-49, on } \\
\text { I-10 }\end{array}$ & $\begin{array}{l}\text { 4:00 am, first day of } \\
\text { evacuation }\end{array}$ & $\begin{array}{l}\text { 12:00 am, Second day } \\
\text { of evacuation }\end{array}$ & \\
\hline $\begin{array}{c}\text { Eastbound I-10 } \\
\text { between New Orleans to } \\
\text { Laplace, LA } \\
\end{array}$ & $\begin{array}{l}\text { 12:00 am, first day of } \\
\text { evacuation }\end{array}$ & $\begin{array}{l}\text { 12:00 am, Second day } \\
\text { of evacuation }\end{array}$ & \multirow{4}{*}{ Plan 2} \\
\hline $\begin{array}{l}\text { Northbound I-10/I-55 } \\
\text { between Hammond, LA } \\
\text { and Mississippi }\end{array}$ & $\begin{array}{l}\text { 12:00 am, first day of } \\
\text { evacuation }\end{array}$ & $\begin{array}{l}\text { 12:00 am, Second day } \\
\text { of evacuation }\end{array}$ & \\
\hline $\begin{array}{l}\text { Northbound I-59, north } \\
\text { to the I-10/I-12/I-59 } \\
\text { interchange }\end{array}$ & $\begin{array}{l}\text { 12:00 am, first day of } \\
\text { evacuation }\end{array}$ & $\begin{array}{l}\text { 12:00 am, Second day } \\
\text { of evacuation }\end{array}$ & \\
\hline $\begin{array}{l}\text { Northbound I-49, on } \\
\text { I-10 }\end{array}$ & $\begin{array}{l}\text { 12:00 am, first day of } \\
\text { evacuation }\end{array}$ & $\begin{array}{l}\text { 12:00 am, Second day } \\
\text { of evacuation }\end{array}$ & \\
\hline
\end{tabular}

Table 2 summarizes the test scenarios and showed the total demand generated by the hypothetical storms. It also displayed the average travel time estimated by the TRANSIMS simulation model. From Table 2 it is apparent that average travel speed (ATS) was inversely related to demand. As network demand increased, average travel speed (ATS) decreased. This is logical and would be expected in any network; emergency condition or daily peak hour.

Table 2. Evacuation Scenarios and Average Travel Speed (ATS)

\begin{tabular}{|c|c|c|c|c|}
\hline Scenario & $\underline{\text { Storm }}$ & $\frac{\text { Contraflow }}{\underline{\text { Plan }}}$ & $\begin{array}{c}\frac{\text { Evacua }}{\text { tion }} \\
\frac{\text { Demand }}{\text { (trips) }}\end{array}$ & $\frac{\underline{\text { Simulat }}}{\underline{\text { ed ATS }}}$ \\
\hline Scenario 1.0-1 & $\underline{1}$ & $\underline{\text { No Plan }}$ & $\underline{454,173}$ & $\underline{52}$ \\
\hline Scenario 1.0-2 & $\underline{1}$ & No Plan & 494,654 & $\underline{49}$ \\
\hline Scenario 1.0-3 & $\underline{1}$ & No Plan & 584,602 & $\underline{42}$ \\
\hline Scenario 1.0-4 & $\underline{1}$ & No Plan & $\underline{674,518}$ & $\underline{31}$ \\
\hline Scenario 1.1-1 & $\underline{1}$ & $\underline{\text { Plan } 1}$ & $\underline{454,173}$ & $\underline{48}$ \\
\hline Scenario 1.1-2 & $\underline{1}$ & $\underline{\text { Plan1 }}$ & $\underline{494,654}$ & $\underline{44}$ \\
\hline Scenario 1.1-3 & $\underline{1}$ & $\underline{\text { Plan } 1}$ & $\underline{584,602}$ & $\underline{41}$ \\
\hline Scenario 1.1-4 & $\underline{1}$ & Plan 1 & $\underline{674,518}$ & $\underline{32}$ \\
\hline Scenario 1.2-1 & $\underline{1}$ & $\underline{P l a n} 2$ & $\underline{454,173}$ & $\underline{48}$ \\
\hline Scenario 1.2-2 & $\underline{1}$ & Plan 2 & 494,654 & $\underline{44}$ \\
\hline Scenario 1.2.3 & $\underline{1}$ & $\underline{\text { Plan } 2}$ & $\underline{584,602}$ & $\underline{42}$ \\
\hline Scenario 1.2-4 & $\underline{1}$ & Plan 2 & $\underline{674,518}$ & $\underline{30}$ \\
\hline Scenario 2.2-1 & $\underline{2}$ & Plan 2 & $\underline{195,355}$ & $\underline{60}$ \\
\hline Scenario 2.2-2 & $\underline{2}$ & $\underline{\text { Plan } 2}$ & $\underline{244,177}$ & $\underline{53}$ \\
\hline Scenario 2.2-3 & $\underline{2}$ & $\underline{P l a n} 2$ & 293,043 & $\underline{43}$ \\
\hline Scenario 2.2-4 & $\underline{2}$ & Plan 2 & $\underline{341,866}$ & $\underline{44}$ \\
\hline Scenario 2.2-5 & $\underline{2}$ & $\underline{\text { Plan } 2}$ & $\underline{390,704}$ & $\underline{38}$ \\
\hline Scenario 2.2-6 & $\underline{2}$ & Plan 2 & $\underline{439,542}$ & $\underline{30}$ \\
\hline Scenario 2.2-7 & $\underline{2}$ & $\underline{P l a n} 2$ & $\underline{488,380}$ & $\underline{25}$ \\
\hline
\end{tabular}




\section{Experimental Results}

To calculate the network productivity, an estimate of average network velocity as function of total demand was required, $v(n)$. This function was estimated by plotting the ATS simulated against the total demand and econometrically fitting a curve to the data points. Because the form of the $v(n)$ was unknown, four functions forms were evaluated: linear, parabolic, logarithmic (natural $\log$ ) and sigmoidal; their general forms are given in Equations (7) through (10). While it cannot be known if the true form of the function $v(n)$ was one of the four fitted curves in this research, these functions fit sufficiently well to estimate the evacuation productivity function. The results of fitting the four functions to the ATS data, their parameters and resulting $\mathrm{R}^{2}$ values are shown in Table 3.

Linear:

$$
v(n)=a n+b
$$

Parabolic:

$$
v(n)=a n^{2}+b n+c
$$

Logarithmic:

$$
v(n)=\operatorname{aln}(n)+b
$$

Sigmoidal:

$$
v(n)=60(a)\left(1-\frac{1}{1+e^{-n+b}}\right)
$$

\begin{tabular}{|c|c|c|c|c|c|c|c|c|c|c|c|c|c|}
\hline \multirow[t]{2}{*}{ Sce. } & \multicolumn{3}{|c|}{ Linear } & \multicolumn{4}{|c|}{ Parabolic } & \multicolumn{3}{|c|}{ Logarithmic } & \multicolumn{3}{|c|}{ Sigmoidal } \\
\hline & $a$ & $b$ & $R^{2}$ & $a$ & $b$ & $\mathrm{c}$ & $R^{2}$ & $a$ & $b$ & $R^{2}$ & $a$ & $b$ & $R^{2}$ \\
\hline $1.0-1$ & \multirow{4}{*}{$\stackrel{?}{\stackrel{p}{q}}$} & \multirow{4}{*}{\begin{tabular}{ll}
$n$ & \multirow{n}{n}{} \\
$n$ & $\vdots$ \\
2 & $=$
\end{tabular}} & \multirow{4}{*}{$\stackrel{\partial}{\sigma}$} & \multirow{4}{*}{$\bar{\sigma}$} & \multirow{4}{*}{$\stackrel{a}{\stackrel{I}{I}}$} & \multirow{4}{*}{ 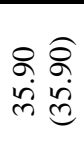 } & \multirow{4}{*}{$\stackrel{\partial}{\circ}$} & \multirow{4}{*}{$\frac{\infty}{i}$} & \multirow{4}{*}{ 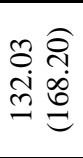 } & \multirow{4}{*}{$\hat{\sigma}$} & \multirow{4}{*}{$\begin{array}{l}+ \\
0 \\
0\end{array}$} & \multirow{4}{*}{ 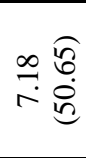 } & \multirow{4}{*}{$\stackrel{\circ}{\circ}$} \\
\hline $1.0-2$ & & & & & & & & & & & & & \\
\hline $1.0-3$ & & & & & & & & & & & & & \\
\hline $1.0-4$ & & & & & & & & & & & & & \\
\hline 1.1-1 & \multirow{4}{*}{$\underset{\hat{\varphi}}{\hat{i}}$} & \multirow{4}{*}{\begin{tabular}{ll}
3 & \multirow{6}{0}{} \\
$\infty$ & 0 \\
\hdashline & 0
\end{tabular}} & \multirow{4}{*}{$\stackrel{\circ}{\circ}$} & \multirow{4}{*}{ 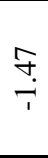 } & \multirow{4}{*}{$\begin{array}{l}+ \\
\text { a } \\
\text { o }\end{array}$} & \multirow{4}{*}{$\begin{array}{l}\vec{\infty} \\
\dot{\infty} \\
\dot{\sim} \\
\tilde{\infty}\end{array}$} & \multirow{4}{*}{$\hat{a}$} & \multirow{4}{*}{ 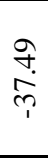 } & \multirow{4}{*}{$\begin{array}{l}\infty \\
\infty \\
\infty \\
\dot{0} \\
\stackrel{0}{=}\end{array}$} & \multirow{4}{*}{$\stackrel{\Delta}{\stackrel{\theta}{\theta}}$} & \multirow{4}{*}{ o̦ } & \multirow{4}{*}{ dु } & \multirow{4}{*}{ } \\
\hline $1.1-2$ & & & & & & & & & & & & & \\
\hline 1.1-3 & & & & & & & & & & & & & \\
\hline $1.1-4$ & & & & & & & & & & & & & \\
\hline $1.2-1$ & \multirow{4}{*}{$\frac{\sqrt{n}}{r}$} & & & & & & & & & & & & \\
\hline $1.2-2$ & & 寸 㠻 & $\approx$ & 8 & q & $\begin{array}{lll}\infty & \infty \\
\infty & \infty \\
\infty & 0\end{array}$ & ஃ & $\bar{n}$ & 0 & $\infty$ & $\infty$ & $m \hat{0}$ & $\hat{s}$ \\
\hline $1.2-3$ & & $\begin{array}{ccc}\pi & 0\end{array}$ & $\ddot{0}$ & $\stackrel{9}{1}$ & $\hat{\imath}$ & $\Rightarrow$ & $\ddot{\theta}$ & 7 & $\Xi m$ & $\ddot{\theta}$ & $\ddot{0}$ & $\therefore g$ & $\ddot{\theta}$ \\
\hline $1.2-4$ & & & & & & & & & & & & & \\
\hline $2.2-1$ & & & & & & & & & & & & & \\
\hline $2.2-2$ & & & & & & & & & & & & & \\
\hline $2.2-3$ & & $\stackrel{\infty}{0}$ & & & & & & & & & & & \\
\hline $2.2-4$ & $\stackrel{\text { 巳 }}{\rightarrow}$ & $\underbrace{\infty}_{0}$ & $\hat{s}$ & n్ & $\ddot{r}$ & $\circ \stackrel{\circ}{+}$ & 5 & "n & กิ & 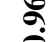 & $\overline{0}$ & $\stackrel{\infty}{\dddot{m}}$ & $\check{\Omega}$ \\
\hline $2.2-5$ & 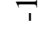 & 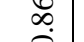 & & & & $\infty \infty$ & & & & & & & \\
\hline $2.2-6$ & & $\infty$ & & & & & & & & & & & \\
\hline 2.2-7 & & & & & & & & & & & & & \\
\hline
\end{tabular}

Table 3. Curve Fitting Results

The fitted functions had $\mathrm{R}^{2}$ values in the range of 0.88 to 0.99 , indicating the fitted curves were appropriately selected. In addition to the parameters $\mathrm{a}, \mathrm{b}$ and $\mathrm{c}$ the value of the $y$-axis intercept is shown in parenthesis for each scenario. This value was the estimated average free flow speed of the network (predicted average travel speed when demand was equal to zero). In terms of model fit, functions which produced unrealistic 
estimates of the average free flow speed indicated poor model performance despite high $\mathrm{R}^{2}$ values. Examples of unrealistic estimates of average free flow speed were values greater than $100 \mathrm{mph}$ or less than zero $\mathrm{mph}$, as these values are outside the domain of realistic outcomes for free flow speed. Both the parabolic and the logarithmic function resulted in unrealistic estimates of free flow speed.

Another indication of model fit was the consistency of the sign (positive or negative) of the parameter coefficient between scenarios. If the curve was an accurate representation of $v(n)$, then the sign for each parameter coefficient should be the same regardless of demand level, contraflow plan or storm track. Otherwise, the model would predict results that vary drastically between scenarios which, was not seen in the simulation results. Referring to Table 3, the parabolic function did not have consistent parameter signs between scenarios and is therefore a poor representation of $v(n)$. The fitted functions for $\mathrm{v}(\mathrm{n})$ were plotted in Figure 3.

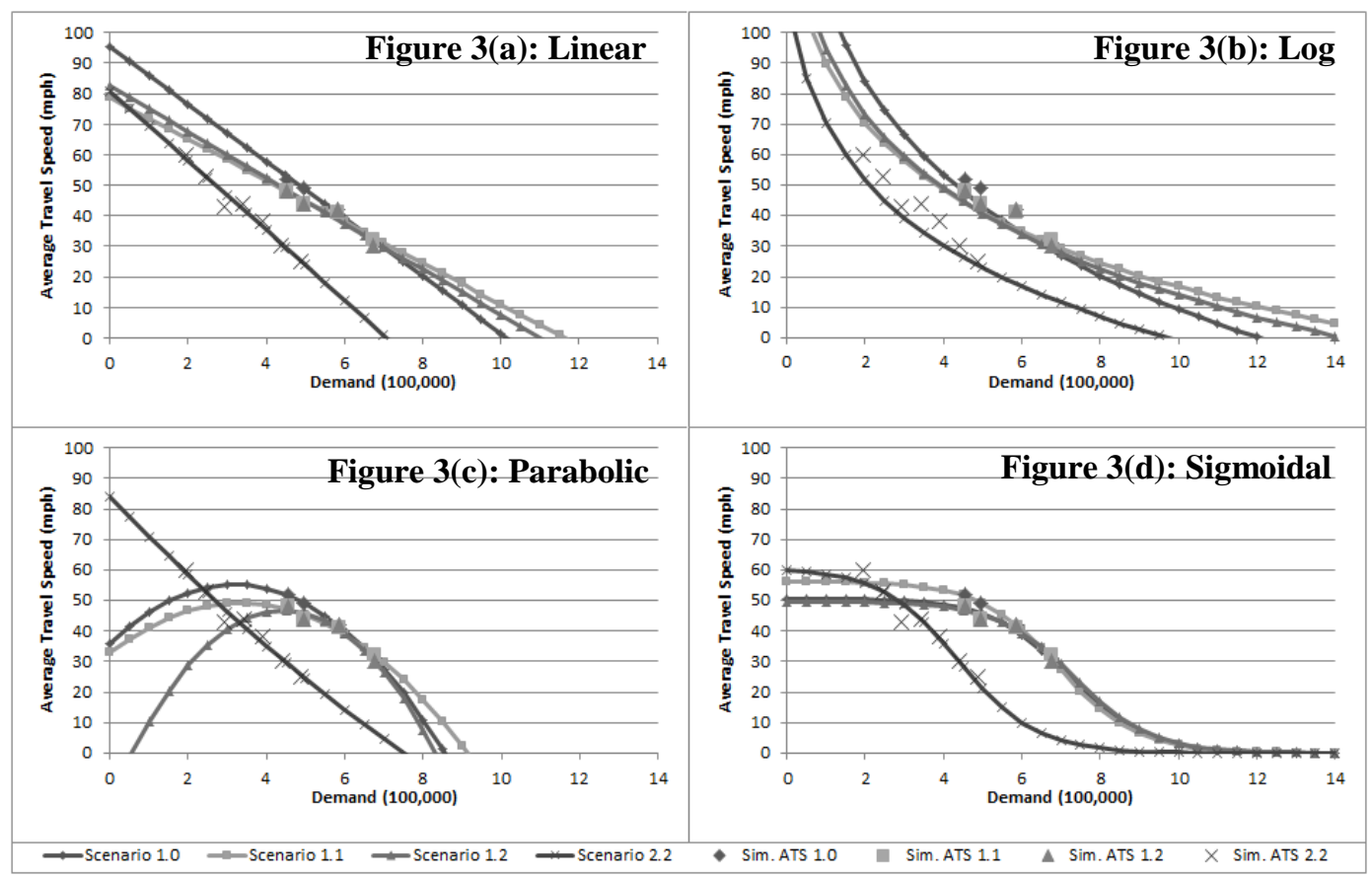

Figure 3. Curve Fitting Results

In addition to the fitted functions, Figure 3 also shows the simulated average travel speed for each scenario, providing a graphical representation of model fit. The figure illustrates the unrealistic estimates of free flow speed given by the logarithmic function and parabolic function. The effect of alternating parameter signs between scenarios was also evident in the graph of the parabolic function, with three of the four scenarios producing concave down functions and the forth producing a concave up function.

Using Equation (6) and the fitted functions for $v(n)$ given in Equations (7) through (10), $\mathrm{q}^{\mathrm{w}}$ as a function of network demand was estimated for each fitted curve. The network productivity per unit network length as a function of demand, $\mathrm{q}^{\mathrm{w}}(\mathrm{n})$ is given in Equations (11) through (14) for each fitted function evaluated in this research. The total lane-miles $\sum_{\mathrm{i}} \mathrm{l}_{\mathrm{i}}$ of the simulated megaregion network was 48,864 miles.

Productivity Function (Linear Fitted Curve):

$q^{w}(n)=\frac{a n^{2}+b n}{\sum_{i} l_{i}}$ 
Productivity Function (Parabolic Fitted Curve):

$q^{w}(n)=\frac{a n^{3}+b n^{2}+c n}{\sum_{i} l_{i}}$

Productivity Function (Logarithmic Fitted Curve):

$$
q^{w}(n)=\frac{n(a \ln (n)+b)}{\sum_{i} l_{i}}
$$

Productivity Function (Sigmoidal Fitted Curve):

$$
q^{w}(n)=\frac{60(a) n\left(1-\frac{1}{1+e^{-n+b}}\right)}{\sum_{i} l_{i}}
$$

The productivity functions were plotted in Figure 4 and display the peaking nature of network productivity. This suggests that there was a demand level at which network productivity was optimal. The optimal demand can be calculated numerically by taking the first derivative of the productivity function, setting it equal to zero, and solving for the demand value. However, for practical purposes, an approximation of the optimal demand can be found by estimating the demand level at the peak of the curves in Figure 4.

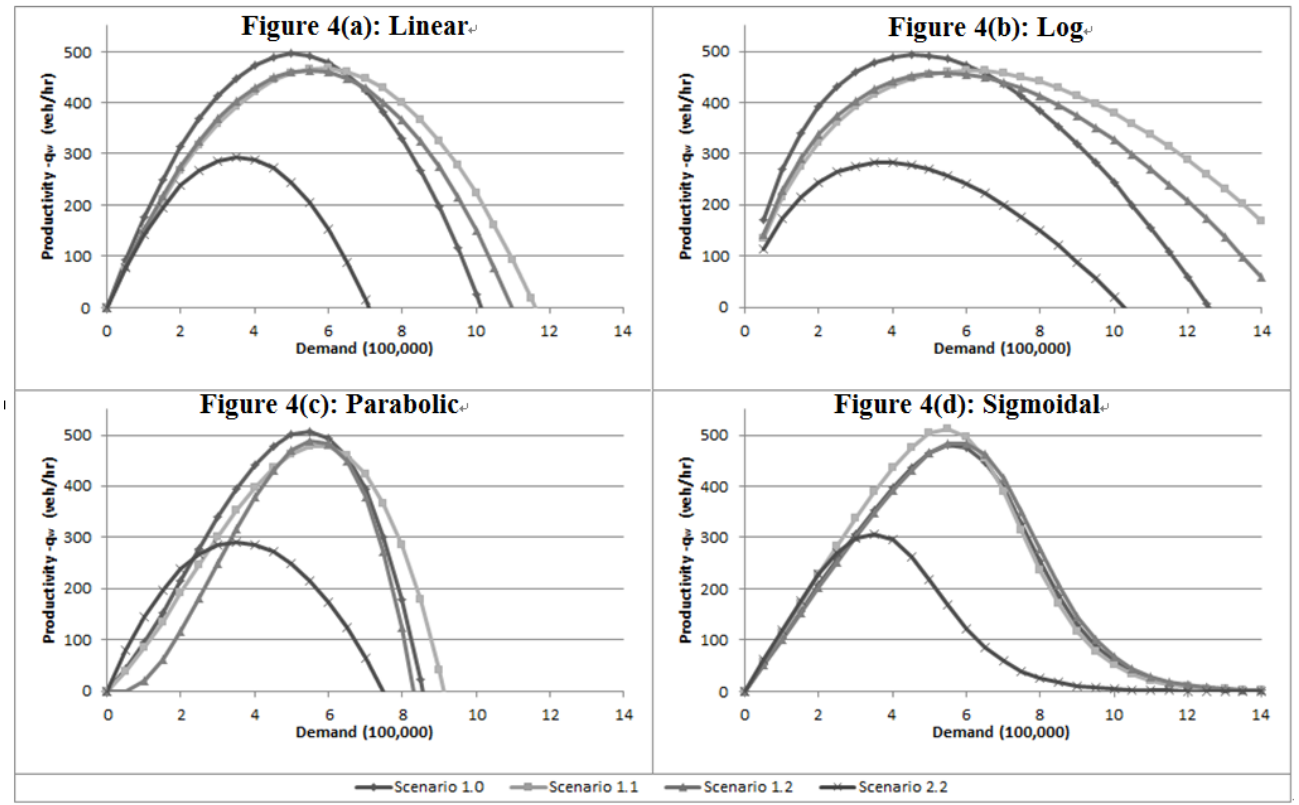

Figure 4. Productivity Curves

The presence of an optimal demand level suggests full network productivity is not realized in two situations. The first is when too many vehicles are on the roadway resulting in congested flows and stopped queues. Congestion hinders the movement of vehicles decreasing average travel speed and lowering network productivity. The second situation lowering network productivity is when too few vehicles are on the roadway. Fewer vehicles traveling at higher speeds create large headways which, from a productivity viewpoint, could be used by other vehicles to increase overall network 
productivity. This may suggest that allowing light to medium congestion during an evacuation can be beneficial, because it increases network productivity and thus total trips completed within a time interval.

With regard to model fit, the limit of the productivity function as demand approaches zero is $\lim _{n \rightarrow 0} q^{w}(n)=0$. Practically, this means that when no vehicles are on the network, no productivity is generated. This was found to be the case for all fitted curves in this research. Moreover, the limit as demand approaches infinity is $\lim _{n \rightarrow \infty} q^{w}(n)=0$. This suggests that when demand was so high in the network, vehicles could hardly move and the average travel speed tended toward zero mph, and correspondingly network productivity tended toward zero vmph. While all four functions trended toward zero as demand increased, only the sigmoidal productivity function approached zero without crossing the $x$-axis. Because average travel speed can never be negative, this attribute of the sigmoidal form of the productivity function was assumed to be the most accurate. This suggests that the true form of the productivity is more closely related to the sigmoidal function given in Equation (14) than any other function examined in this research.

A closer examination of the sigmoidal productivity functions in Figure 4, suggest that all scenarios are nearly identical until total network demand reached about 225,000 vehicles. After which the productivity for scenario 2.2 drops off considerably when compared to other scenarios. This finding suggests that network productivity is a function of road network and independent of individual trip origins and destinations, as was also concluded by Geroliminis and Daganzo (2007). The decrease in network productivity from Scenario 2.2 which corresponds to Strom Track 2 resulted from having fewer destination options for evacuees, concentrating demand on fewer links. This caused average travel speed on these links to decrease, disproportionately, when compared to Scenarios 1.0, 1.1 and 1.2. This suggests that while the productivity function may be independent of origin and destination, limiting number of available shelters (i.e., having fewer destinations) during an evacuation, had a significant effect on the total productivity of the network.

\section{Model Validation}

Traffic simulation models are calibrated and validated to provide a statistical comparison between the simulated environment and the real-world. Due to the magnitude of the megaregion model, the standard methodology for this process could not be applied. Therefore, to confirm the results found in this research, the methodology was performed on an urban grid network. This was done to show that the evacuation productivity function is not unique to the megaregion model developed for this research and that the methodology can be applied to other study areas of varying size and structure.

The validation road network was an urban grid consisting of 30 horizontal roads and 34 vertical roads. Each road was classified as an urban road type and consisted of four lanes (two in each direction). The grid network spanned 41 miles horizontally and 42 miles vertically and had a total lane length $\sum_{\mathrm{i}} \mathrm{l}_{\mathrm{i}}$ of 10,902 miles. For the purpose of validation, only one shelter location to the North was used. The simulation was conducted for nine demand levels varying between 235,178 vehicles to 470,357 vehicles. The simulated results are given in Table 4. Similar to the megaregion model, a general downward trend in average travel time was observed as demand increased. 
Table 4. Validation Network Average Travel Speed (ATS)

\begin{tabular}{|l|c|c|c|c|c|c|c|c|c|}
\hline Demand (veh) & $\begin{array}{c}235 \\
\text { K }\end{array}$ & $\begin{array}{c}305 \\
\text { K }\end{array}$ & $\begin{array}{c}338 \\
\text { K }\end{array}$ & $\begin{array}{c}352 \\
\text { K }\end{array}$ & $\begin{array}{c}376, \\
\text { K }\end{array}$ & $\begin{array}{c}399 \\
\text { K }\end{array}$ & $\begin{array}{c}423 \\
\text { K }\end{array}$ & $\begin{array}{c}446 \\
\text { K }\end{array}$ & $\begin{array}{c}470 \\
\text { K }\end{array}$ \\
\hline $\begin{array}{l}\text { Sim. ATS } \\
\text { (mph) }\end{array}$ & 63 & 58 & 43 & 40 & 28 & 24 & 19 & 17 & 14 \\
\hline
\end{tabular}

From the average travel speed results of the validation network a sigmoidal function of the form given in Equation (10), was fitted. The a, $\mathrm{b}$ and $\mathrm{R}^{2}$ were calculated to be 1.741, 2.938 and 0.94 , respectively. The average free flow speed of the network estimated by the fitted curve was approximately $99 \mathrm{mph}$. This may suggest that the model had difficultly estimating free flow speed which may have resulted from the uniformity of the grid network.

The network productivity was calculated using Equation (14). The network productivity of the grid network was graphed alongside the average travel speed estimated by the sigmoidal function in Figure 5. This function was consistent with regard to the shape and magnitude of the productivity function estimated for the megaregion network seen in Figure 4, suggesting that the sigmoidal estimate of network productivity, Equation (14) was an adequate approximation.

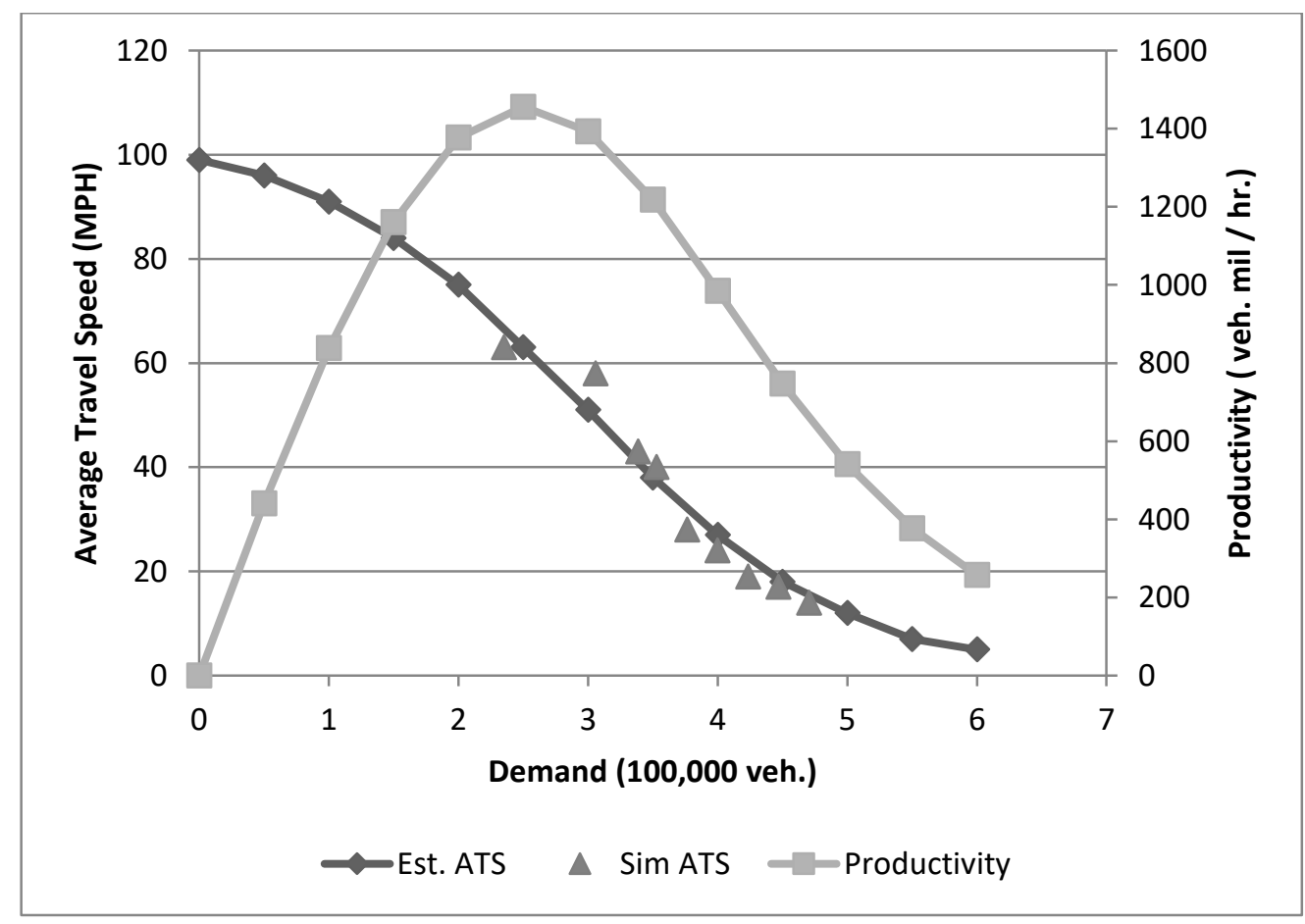

Figure 5. Validation Network Results

The application of the research methodology to a grid network showed that the network productivity function was not unique to the megaregion model. This suggests that the research methodology is applicable to other traffic networks and may be independent of size and structure. The sigmoidal approximation for productivity, $\mathrm{q}^{\mathrm{w}}(\mathrm{n})$ given in Equation (14) was shown to be a realistic representation in both the megaregion and grid simulations, indicating that it is a valid practical assumption for estimating network productivity. 


\section{Conclusion}

As the speed and power of computational tools to analyze ever larger and more complex transportation networks increases, the volume and level of detail of the output data they produce will, inevitably, also grow. Today, there are a variety of tools available to simulate the movements and characteristics of individual vehicles and pedestrians over vast geographic areas and long durations. One of the most useful applications of these large-scale systems is for the simulation of regional evacuations. Evacuation traffic simulations provide critical insights to transportation and emergency management officials who plan and manage emergency response to catastrophic disasters that can threaten millions of people. Unfortunately, the results of these simulations can be overwhelming. Often, output data file sizes are measured in multiple terabytes making it difficult to assess the overall conditions of large-scale networks.

In this study, the researchers sought to address these issues and push the limits of traffic modeling by simulating the traffic processes associated with an evacuation of a megaregion-sized network. This was done to assess the operational conditions of the network and operational processes of the system using the emerging concept of "Network Productivity" and "Trip Completion". The motivation for this work was based on the recent recommendations by the Federal Emergency Management Agency (FEMA) for states and cities to plan for the "maximum of maximum" disasters [20] and the desire by transportation agencies to examine the effects of emergency demand and capacity management techniques on mass evacuations over multi-state areas. Recent studies, however, have revealed problems of evaluating data produced by simulations on this scale. As a result there is a need for performance indicators and techniques that allow systemwide comparisons of alternatives and performance.

The findings of this research are significant in several respects. Most notably, they demonstrate the application of a novel performance and computational technique to assess the operation of traffic networks, system-wide, independent of their size or duration of analysis. This technique is ideal for evacuation planning and alternative comparison in megaregions. By estimating a function for "network productivity," emergency management and transportation decision-makers can use "trip completion" as a measure of evacuee departures out of a threat area. This permits a systematic and qualitative basis for assessing evacuee demand management (staged evacuations, route closures, etc), traffic control/management (contraflow, turn restrictions, ramp closures, etc.,) measures that can improve regional mass evacuations.

Using a comparison of the megaregion and validation networks the form of the network productivity function was found to consistent, suggesting the sigmoidal function, Equation (14) to be reasonable assumption. An interesting attribute of the network productivity function was that it was likely dependent upon the road network configuration and demand only, suggesting productivity is independent of origin (threat area) and destination (shelter location). The results of this research also suggest that evacuation network productivity and, by extension, evacuation trip completion exhibit a peaking characteristic. If true, this would indicate that network productivity can be maximized on a macroscopic scale, likely through network demand metering. The benefits of demand metering for interstate freeways is a well-known concept in traffic engineering. However, applying these techniques on a large (megaregion) scale has not been explored in prior research. Previous research on phased evacuation $[12,21]$ has shown demand metering to be an effective evacuation strategy but no study has yet addressed why it is successful or provided a formulation to describe its impact.

By building on the work of Geroliminis and Daganzo (2007), this research has defined a functional form for evacuation network productivity and illustrated its peaking nature as a function of demand. With knowledge of the optimal network demand, emergency planners can develop evacuation management plans which reach and maintain traffic at an 
optimal demand level. The results of this research indicate that when this optimal demand level is exceeded, evacuees are likely to experience inordinately lengthy delays such as those observed during the Hurricane Rita evacuation of Houston in 2005. Conversely this research suggests that demand levels that are below the optimal level will result in reduced overall network productivity and fewer trips completed per time interval. All combined, these finding suggest light to medium congestion produces the highest trip completion rate (and evacuation clearance) during an emergency, indicating that free flow conditions are not optimal from an overall network productivity viewpoint.

In general, it was seen that the productive function appeared to take the form of a macroscopic fundamental diagram. With this knowledge going forward, curve fitting should resemble those approaches more traditionally related to the Greenshields models and the Van Aerde models. This suggest that more research is needed to investigate the relationship between network productivity and the fundamental diagrams, both on a microscopic and macroscopic scale.

In conclusion, it is recognized this theoretical approach can present difficulties in actual practice. To meter demand under an actual emergency condition, evacuee entries into the system would have to be restricted, spatially and/or temporally, to prevent sudden surges in demand from overwhelming the network. As a practical matter this could present operational and ethical dilemmas because some portion of a threatened population would have to be physically prohibited from fleeing.

\section{Acknowledgments}

The authors want to thank the Gulf Coast Center for Evacuation and Transportation Resiliency; a United State Department of Transportation sponsored University Transportation Center and a member of the Maritime Transportation Research and Education Center (MarTREC) for supporting the work presented herein.

\section{References}

[1] T. Urbanik, A. Desrosier, M. K. Lindell and C. R. Schuller, "Analysis of Techniques for Estimating Evacuation Times for Emergency Planning Zones", NUREGrCR-1745, U.S. Nuclear Regulatory Commission, Washington, DC, (1980).

[2] Z. Zhang, K. Spansel and B. Wolshon, "Megaregion Network Simulation for Evacuation Analysis", Transportation Research Record, Print, (2013), pp. 161-170.

[3] N. Gerolimins and C. F. Daganzo, "Macroscopic modeling of traffic in cities", TRB $86^{\text {th }}$ Annual Meeting, \#07-0413, Washington D.C., (2007).

[4] J. Gottman, "Megalopolis: The Urbanized Northeastern Seaboard of the United States", New York: Twentieth Century Fund, (1961).

[5] Y. Sheffi, H. S. Mahmassani and W. Powell, "NETVAC: A Transportation Network Evacuation Model", Internal report, Center for Transportation Studies, Massachusetts Institute of Technology, United States, (1980).

[6] G. Theodoulou, "Contraflow Evacuation on the Westbound I-10 out of the City of New Orleans", Master Thesis, Louisiana State University, Baton Rouge, LA, (2003).

[7] E. Lim and B. Wolshon, "Modeling and Performance Assessment of Contraflow Evacuation Termination Points", Transportation Research Record, vol. 1922, (2005).

[8] Y. C. Chiu, "Traffic Scheduling Simulation and Assignment for Area-Wide Evacuation", 2004 IEEE Intelligent Transportation Systems Conference, Washington, D.C., (2004) October.

[9] KLD (1984) "Formulations of the DYNEV and I-DYNEV Traffic Simulation Models Used in ESF", Federal Emergency Management Agency.

[10] A. G. Hobeika and B. Jamei, "MASSVAC: A Model for Calculating Evacuation Times under Natural Disasters", Computer Simulation in Emergency Planning, La Jolla, Society of Computer Simulation, (1985).

[11] A. Kirschenbaum, "Warning and Evacuation During a Mass Disaster: A Multivariate Decision-Making Model", International Journal of Mass Emergencies and Disasters, vol. 10, no. 1, (1992), pp. 91-114.

[12] Y. Chiu, H. Zheng, J. A. Villalobos, W. Peacock and R. Henk, "Evaluating Regional Contra-Flow and Phased Evacuation Strategies for Texas Using a Large-Scale Dynamic Traffic Simulation and Assignment Approach", Journal of Homeland Security and Emergency Management, vol. 5, no. 1, Article 34, (2008). 
[13] V. V. Dixit, T. Montz and B. Wolshon, "Validation Techniques for Region-Level Microscopic Mass Evacuation Traffic Simulations", Transportation Research Record, vol. 2229, (2011), pp. 66-74.

[14] C. F. Daganzo, "Improving city mobility through gridlock control: an approach and some ideas", U.C. Berkely Center for Future Urabn Transport Working Paper UCB-ITS-VWP-2005-1, (2005).

[15] C. F. Daganzo, "Urban gridlock: Macroscopic Modeling and mitigation approaches", Transportation Research Part B, vol. 41, no. 1, (2007), pp. 49-62.

[16] N. Gerolimins and C. F. Daganzo, "Existence of urban-scale macroscopic fundamental diagrams: Some experimental findings", Transportation Research Part B, vol. 42, no. 2008, (2008), pp. 759-770.

[17] G. Cheng, C. Wilmot and E. Baker, "A Destination Choice Model for Hurricane Evacuation”, 88th Annual Meeting of the Transportation Research Board (CD-ROM), Washington, D.C., (2008).

[18] R. Gudishala, "Development of a time dependent, audio-visual, stated choice method of data collection for hurricane evacuation behavior", Ph.D. dissertation, Louisiana State University, (2011).

[19] National Ocean and Atmospheric Administration Website. http://www.csc.noaa.gov/hurricanes/\#, Accessed, (2012) August 10.

[20] "Whole Community: Planning for the Unthinkable Tabletop Exercise |FEMA.gov." Whole Community: Planning for the Unthinkable Tabletop Exercise | FEMA.gov. Federal Emergency Management Agency (FEMA), 1 Jan. 2012. Web. 5 May 2014. <http://www.fema.gov/medialibrary/assets/documents/26762?fromSearch=fromsearch\&id=5932>.

[21] Z. Zhang, K. Spansel and B. Wolshon, "Effect of Phased Evacuations in Megaregion Highway Networks", In Transportation Research Board 93rd Annual Meeting, no. 14-5493, (2014).

[22] C. F. Daganzo, V. V. Gayah and E. J. Gonzales, "Macroscopic relations of urban traffic variables: bifurcations, multivaluedness and instability", Transportation Research Part B: Methodological, vol. 45, (2011), pp. 278-288.

[23] X. Wu, H. X. Liu and N. Geroliminis, "An empirical analysis on the arterial fundamental diagram", Transportation Research Part B: Methodological, vol. 45, pp. 255-266.

[24] M. Keyvan-Ekbatani, A. Kouvelas, I. Papamichail and M. Papageorgiou, "Exploiting the fundamental diagram of urban networks for feedback-based gating", Transportation Research Part B: Methodological, vol. 46, (2012), pp. 1393-1403.

[25] C. Buisson and C. Ladier, "Exploring the impact of homogeneity of traffic measurements on the existence of macroscopic fundamental diagrams", Transportation Research Record: Journal of the Transportation Research Board, vol. 2124, (2009), pp. 127-136.

[26] A. Mazloumian, N. Geroliminis and D. Helbing, "The spatial variability of vehicle densities as determinant of urban network capacity", Philosophical Transactions of the Royal Society of London A: Mathematical, Physical and Engineering Sciences, vol. 368, pp. 4627-4647.

[27] N. Geroliminis and J. Sun, "Properties of a well-defined macroscopic fundamental diagram for urban traffic", Transportation Research Part B: Methodological, vol. 45, (2011b), pp. 605-617.

[28] L. Zhu, L. Yu and G. Song, "MFD based investigation into macroscopic traffic status of urban networks and its influencing factors", Journal of South China University of Technology (Natural Science Edition, vol. 40, (2012), pp. 138-146.

[29] S. K. So and C. F. Daganzo, "Managing evacuation routes", Transportation Research Part B: Methodological, vol. 44, (2010), pp. 514-520.

[30] C. F. Daganzo and S. K. So, "Managing evacuation networks", Transportation Research Part B: Methodological, vol. 45, (2011), pp. 1424-1432.

[31] Z. Zhang, K. Spansel, V. Dixit and B. Wolshon, "Performance characteristics of megaregion traffic networks during mass evacuations", International Journal of Transportation, vol. 2, (2014), pp. 53-72.

\section{Authors}

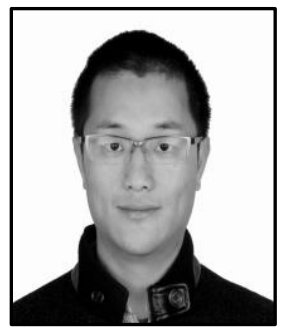

Zhao Zhang, Ph.D., Dr. Zhao Zhang is an assistant professor at Behihang University, Beijing, China. Dr. Zhang earned his $\mathrm{Ph} . \mathrm{D}$. in Transportation Engineering from Southwest Jiaotong University specializing in Transportation Engineering. Dr Zhang has done postdoctoral research at Tsinghua University from 2013 to 2015, and has published several papers in top transportation journals such as Transportation Research Part B and Part C. Dr Zhang's research areas cover evacuation traffic modeling and optimization, traffic simulation, discrete choice analysis and GPS data mining and map matching. Prior to his arrival at BUAA, Dr. Zhang has done research collaborations with MPO of New Orleans and Houston, Ford Auto, AutonNavi, and so on. 


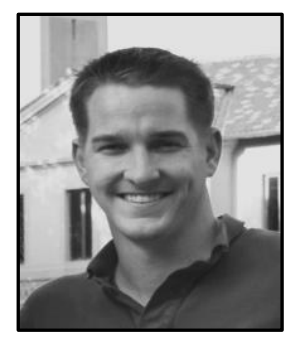

Scott Parr, Ph.D., EIT, Dr. Scott Parr is an assistant professor at California State University, Fullerton. Dr. Parr earned his Ph.D. in Civil Engineering from Louisiana State University specializing in Transportation Engineering and Emergency Management. Dr. Parr is published in several peer reviewed journals and has participated as an expert panelist at conferences and workshops around the nation. Dr. Parr also serves as a reviewer for several expert journals such as the Transportation Research Record, Journal of Emergency Management and ASCE's Natural Hazards Review. Dr. Parr has led research collaborations with the United States Department of Transportation, Department of Homeland Security, Transit Security Administration and Sandia National Laboratory's Radiological Consequence Management and Response Technologies Department. Prior to his arrival at CSUF, Dr. Parr was the Associate Director of Research at the Gulf Coast Center for Evacuation and Transportation Resiliency at Louisiana State University.

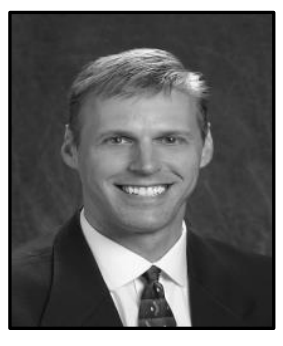

Brian Wolshon, Ph.D., P.E., PTOE, Dr. Wolshon is the Edward A. and Karen Wax Schmitt Distinguished Professor of Civil Engineering at Louisiana State University and the founding Director of the Gulf Coast Research Center for Evacuation and Transportation Resiliency. His teaching and research activities encompass a range of areas related to highway design, safety, and traffic operations - most notably the planning, design, operation, and management of transportation systems for emergency and major event conditions. In 2001, Dr. Wolshon founded and has since chaired Transportation Research Board of the National Academies Committee on Emergency Evacuation. He has authored numerous federal reports related to evacuation planning and engineering and served as an expert consultant to dozens of federal, state, and local government agencies; national laboratories; and engineering firms throughout the United States. He also been interviewed by more the 100 media outlets including The Discovery Channel, CNN, CNBC, MSNBC, Fox News, NPR, The New York Times, USA Today, and the Times of London among many others. 
International Journal of Transportation

Vol.4, No.3 (2016) 